\title{
Irrigação de pastagem: atualidade e recomendações para uso e manejo
}

\section{Carlos Augusto Brasileiro de Alencar ${ }^{1}$, Fernando França da Cunha ${ }^{1}$, Carlos Eugênio Martins ${ }^{2}$, Antônio Carlos Cóser $^{2}$, Wadson Sebastião Duarte da Rocha ${ }^{2}$, Rodrigo Antônio Silva Araújo ${ }^{1}$}

1 Departamento de Engenharia Agrícola - UFV/Viçosa.

2 Centro Nacional de Pesquisa Gado de Leite - Embrapa/Juiz de Fora.

RESUMO - Nos últimos anos tem sido grande o interesse pela irrigação de pastagens e pelos temas engenharia, custo de equipamento, custo de manutenção de energia elétrica, demanda de água e de energia elétrica, manejo da irrigação e fertirrigação. Tal interesse tem aumentado a demanda por informações e recomendações práticas que ajudem a esclarecer os aspectos importantes como a escolha do sistema de irrigação, a evapotranspiração potencial (ETo), o coeficiente da cultura (Kc); a evapotranspiração da cultura (ETc), o turno de rega (TR), a escolha de aspersores, a vazão ( $\mathrm{m}^{3} / \mathrm{h}$.ha), a potência (cv/ha) e os parâmetros referentes à estimativa de lâmina de irrigação tais como: capacidade de campo (Cc), ponto de murcha permanente (Pm), densidade do solo (Ds), profundidade efetiva do sistema radicular (Z), fator de disponibilidade de água do solo (f) e eficiência de aplicação (Ea). Neste contexto o presente trabalho reúne informações fundamentais para implantação e condução segura de irrigação de pastagem. As informações disponibilizadas são frutos de parcerias entre várias instituições (Universidade Federal de Viçosa - UFV, Universidade Federal de Tocantins - UFT, Universidade Vale do Rio Doce - UNIVALE e Centro Nacional de Pesquisa de Gado de Leite - EMBRAPA), tanto em trabalhos de pesquisa e extensão, como também experiência de campo da equipe. Os objetivos desta publicação são: difundir novos conhecimentos científicos, com experiência de campo, em irrigação de pastagem e enfocar, de maneira prática e sucinta, como, quanto e quando se deve e quanto custa fertirrigar pastagens, estimulando novas observações, facilitando, assim, as decisões com um todo, potencializando a rentabilidade da pecuária de leite e de corte.

Palavras-chave: aspersão, coeficiente da cultura, evapotranspiração, fertirrigação, lâmina de irrigação, sistema radicular

\section{Pasture irrigation: present and recommendations for use and management}

\begin{abstract}
In the last years has been a great interest in the irrigation of pastures and the engineering issues, cost of equipment, cost of maintenance of electricity, demand for water and electricity, management irrigation and fertigation. This interest has increased the demand for information and practical advice to help clarify the important aspects as the choice of irrigation system, the potential evapotranspiration (ETo), the culture of coefficient (Kc), the evapotranspiration of the crop (ECc), the shift of water (SW), the selection of sprinklers, the flow (m3/h.ha), power (hp / ha) and the parameters for estimation of irrigation such as: field capacity $(\mathrm{Fc})$, permanent wilting point (Pwp), bulk density (Bd), effective depth of the root system (Z) availability of soil water factor (f) and efficiency of application (EA). In this context the present work presents key information for deployment and conduct of safe irrigation of pasture togrther. The information available are fruit of partnerships between various institutions (Universidade Federal de Viçosa - UFV, Universidade Federal de Tocantins - UFT, University Vale do Rio Doce - UNIVALE and Centro Nacional de Pesquisa de Gado de Leite - Embrapa), in search of work and extension, as well as experience of field staff. The objectives of this publication are: disseminating scientific knowledge, with experience in the field, in irrigation of pasture and focus, with a practical and succinct way, how, how many and when and how much should fertirrigated pastures cost, stimulating new observations thus facilitating the decisions as a whole, increasing the profitability of livestock for milk and cut.
\end{abstract}

Key Words: crop coefficient, evapotranspiration, fertirrigation, irrigation levels, spraying, root system

\section{Introdução}

Ao se pensar no aumento da produtividade de leite e de carne em nível de propriedade rural, uma das opções que mais têm se destacado refere-se à intensificação da produção a pasto, pelo uso racional de tecnologias relacionadas com o manejo do solo, do ambiente, da planta e do animal.

Ultimamente, tem crescido a utilização da irrigação como forma de aumentar a capacidade produtiva de biomassa das forrageiras tropicais. Entretanto, vale a pena destacar que esta resposta na capacidade produtiva das pastagens, em função da irrigação, está diretamente relacionada com 
fatores climáticos, especialmente temperatura e fotoperíodo.

No Brasil, a irrigação de pastagens não tem sido feita de maneira adequada, podendo levar a aplicação excessiva de água, o que resulta em prejuízos ao ambiente, consumo desnecessário de energia elétrica e de água, lixiviação de nutrientes e maior compactação do solo, repercutindo na diminuição da produção e vida útil da pastagem.

Os objetivos deste trabalho são: difundir novos conhecimentos em irrigação de pastagem e enfocar, de maneira prática e sucinta, como, quanto e quando se deve e quanto custa fertirrigar pastagem, estimulando novas observações, facilitando, assim, as decisões com um todo.

\section{Pesquisas recentes}

Um grupo de pesquisadores formado por estudantes, professores e técnicos das instituições Universidade Federal de Viçosa (UFV), Universidade Federal de Tocantins (UFT), Universidade Vale do Rio Doce (UNIVALE) e do Centro Nacional de Pesquisa de Gado de Leite da EMBRAPA, realizaram recentemente experimentos para avaliar os efeitos das lâminas de irrigação, adubação (convencional e fertirrigação) e épocas climáticas sobre a qualidade e produção de gramíneas forrageiras tropicais. Esses estudados geraram 4 teses de doutorado e diversos trabalhos técnico-científicos. Um fato comum nesses trabalhos, além dos tratamentos, foi a utilização da técnica Line Source Sprinkler Irrigation, animais (vacas mestiças HZ) como ferramenta de corte e a simulação de pastejo para obtenção da produtividade de matéria seca passível de ser consumida. A maior produtividade de matéria seca passível de ser consumida foi de aproximadamente $21.000 \mathrm{~kg} / \mathrm{ha}$.ano, com capim-xaraés fertirrigado, Esses estudos sinalizam taxa de lotação média de 4,2 vacas em lactação por hectare (oito vezes a média do País), custo da dieta de $\mathrm{R} \$ 0,12$ por $\mathrm{kg}$ de MS ou R\$ 0,20 por litro de leite (vacas 8,0 litros/dia).

\section{Revisão dos trabalhos}

Alencar (2007) na região Leste do Estado de Minas Gerais, avaliando o desempenho de seis gramíneas forrageiras tropicais sob diferentes lâminas de irrigação e estações do ano, verificou-se no geral, que o capim-xaraés se destacou por apresentar maior produtividade em relação às demais gramíneas. Esse mesmo autor destacou que o aumento da lâmina de irrigação proporcionou aumento na produtividade de MS apenas na estação outono/inverno e o aumento da dose de adubação nitrogenada não aumentou a produtividade dos capins. Quanto ao efeito proporcionado pela estação do ano, foi verificado que a produtividade de MS foi em geral, maiores na estação primavera/verão em relação à estação outono/inverno.
Cunha (2009) trabalhando na mesma área experimental, porém avaliando apenas o capim-xaraés fertirrigado, observou incrementos na produtividade de MS com aumento da dose de adubação com $\mathrm{N}$ e $\mathrm{K}_{2} \mathrm{O}$.

Oliveira Filho (2007) avaliando os capins Tanzânia e Xaraés no município de Gurupi, TO, verificou aumento da produtividade de MS de ambos capins com o aumento da lâmina de irrigação e adubação com $\mathrm{N}_{\text {e }} \mathrm{K}_{2} \mathrm{O}$.

Em média, nos trabalhos de Alencar (2007) e Cunha (2009), a produtividade de MS obtida na estação outono/ inverno foi de $76 \%$ produzida na estação primavera/verão. No trabalho de Oliveira Filho (2007), essa relação foi de aproximadamente $80 \%$. Essa pequena diferença entre as regiões foi devido os experimentos serem montados em locais de baixa latitude $\left(18^{\circ} 47^{\prime}\right.$ e $11^{\circ} 45^{\prime}$ para Governador Valadares e Gurupi, respectivamente) e altitude (223 e 287 metros para Governador Valadares e Gurupi, respectivamente). A temperatura de inverno nessas regiões é maior que $15^{\circ} \mathrm{C}$ e segundo BURKART (1975), sob condições de temperaturas médias anuais de inverno superiores a esse valor, a taxa de crescimento das pastagens não se apresenta baixa.

Vitor (2006) trabalhando com o capim-elefante em Coronel Pacheco, MG, latitude de $21^{\circ} 35^{\prime}$ e altitude de 435 $\mathrm{m}$, obteve uma produtividade de MS passível de ser consumida na estação outono/inverno de $30 \%$ em relação à produzida na estação primavera/verão.

Recomendaçoes: fatores importantes em projeto e manejo da irrigação

O conhecimento dos fatores que devem ser levados em consideração em um projeto ou manejo da irrigação é de suma importância para o sucesso na utilização da pastagem. Os principais aspectos que devem ser considerados são descritos a seguir.

\section{Quantidade e qualidade da água}

Em projetos de irrigação de pastagem a vazão necessária pode variar de 1.400 a 4.200 litros por hora por hectare irrigado. Ou seja, em um projeto de 10 hectares, a vazão bombeada será em média de 28.000 litros de água por hora $\left(28 \mathrm{~m}^{3} / \mathrm{h}\right)$.

Não fazer análise de água e prover tratamentos adequados pode resultar no fracasso do projeto. Quanto às características que determinam a qualidade da água para irrigação, de acordo com Bernaardo et al. (2007), a água deve ser analisada com relação a seis parâmetros básicos: concentração total de sais solúveis ou salinidade; proporção relativa de sódio, em relação aos outros cátions ou capacidade de infiltração do solo; concentração de 
elementos tóxicos; concentração de bicarbonatos; aspecto de entupimento (rotor e tubulação) e aspecto sanitário.

\section{Planta plani-altimétrica}

As informações planimétricas e altimétricas devem ser levantadas em uma única planta, carta ou mapa e deve fornecer o maior número possível de informações da superfície representada para efeitos de estudo, planejamento e viabilização de projetos. O ideal é ter a planta em arquivo do Autocad (extensão dwg). Ela deve conter informações do posicionamento da água, sua cota do nível mais baixo, estradas, rede de energia elétrica, cercas, afloramentos rochosos e outros detalhes que possam interferir na seleção e no "layout" do sistema (Drumond \& Aguiar, 2005).

\section{Estimativa de evapotranspiração (ET)}

Evapotranspiração é a soma dos componentes de transpiração e evaporação. Sua definição é de fundamental importância em pastagem irrigada, pois estabelece o consumo de água pela mesma e, por conseqüência, a lâmina de irrigação a ser aplicada pelo sistema.

Há vários métodos para determinar a evapotranspiração, os quais, em sua maioria, estimam a evapotranspiração potencial, ou seja, a que ocorre quando não há deficiência de água no solo que limite seu uso pelas plantas. Mas, como é de se esperar, em razão das características intrínsecas de cada cultura, a evapotranspiração potencial varia de cultura para cultura. Assim sendo, verificou-se a necessidade de definir a evapotranspiração potencial para uma cultura de referência (ETo) e a evapotranspiração real (ETc) por cultura. Elas podem ser assim definidas:

ETo - É a evapotranspiração de uma cultura hipotética que cobre todo o solo, em crescimento ativo, sem restrição hídrica nem nutricional (ótimas condições de desenvolvimento), com altura média de $0,12 \mathrm{~m}$, albedo de 0,23 e resistência da superfície de $70 \mathrm{~s} / \mathrm{m}$.

O modelo utilizado como padrão para estimar a ETo é a equação de Penman-Monteith. Apesar de ser complexa, a sua utilização tem sido potencializada com a evolução e disponibilidade das estações meteorológicas automáticas e da Internet (INMET, AGRITEMPO, CPTECMETEOROLOGIA PARA AGRICULTURA, etc).

ETc - É a quantidade de água evapotranspirada por uma determinada cultura, sob as condições normais de cultivo, isto é, sem a obrigatoriedade do teor de umidade permanecer sempre próximo à capacidade de campo.

A ETc é determinada por meio da multiplicação da evapotranspiração de referência (ETo) e de um coeficiente da cultura $(\mathrm{Kc})$ :

$\mathrm{ETc}=\mathrm{ETo} \cdot \mathrm{Kc}$
Nessa equação, têm-se a ETo, que representa a demanda de uma região qualquer, sendo variável de local para local, e o Kc, que é um componente representativo da cultura, variando de acordo com o estádio de desenvolvimento fenológico desta.

No entendimento dos autores desta publicação, com base em resultados de pesquisa e experiência de campo, recomenda-se em irrigação de pastagem Kc prático (único, constante e valor igual a 0,80), para estádio de desenvolvimento entre ciclo de pastejo, onde tanto a evaporação quanto a transpiração são componentes importantes no processo da ETc.

\section{Estimativa de lâmina de irrigação}

Para estimar a lâmina de irrigação em pastagem é necessário definir alguns parâmetros muito utilizados. São eles (Figura 1):

Saturação: a água drenada para baixo da zona radicular, ou para dentro de um dreno, não mais será disponível para a planta.

Capacidade de campo (Cc): é a máxima quantidade de água que o solo pode reter sem causar danos ao sistema.

Um método prático de determinação desse parâmetro é o método de campo, que é determinado em campo, conforme Mantovani et al. (2007).

Outro método para determinar a Ccé o método da curva de tensão (curva característica), que é determinado em laboratório. De acordo com Bernardo et al. (2007) a tensão correspondente à capacidade de campo, dependendo do tipo de solo, pode variar de 1/20 a 1/3 de atm. Em solos típicos do cerrado é comum encontrar a Cc com valores de 1/20 de atm; em solos arenosos, 1/10 de atm; e em solos de textura fina, $1 / 3$ de atm.

Ponto de murcha permanente $(\mathrm{Pm})$ : é definido como o limite inferior de armazenamento de água no solo (Figura 1). Nesse ponto é dito que a água já não está mais disponível

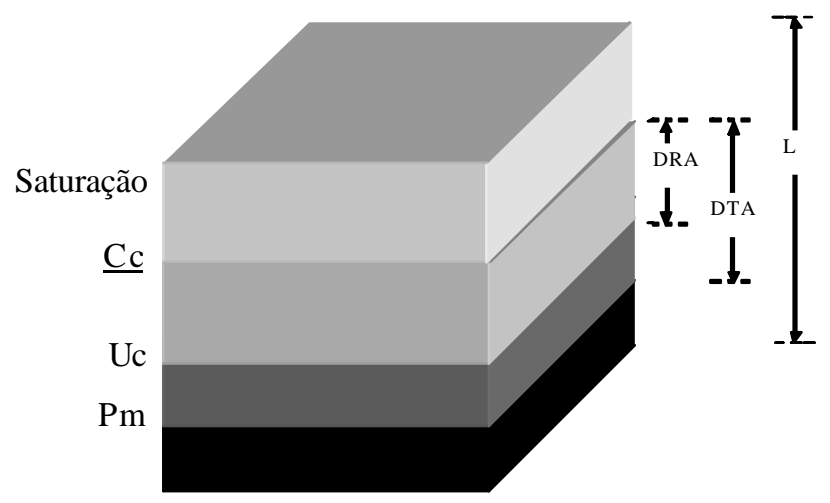

Figura 1 - Diagrama da disponibilidade de água no solo em função dos seus parâmetros físico-hídricos e da planta. 
às plantas, na qual a força de retenção que o solo exerce sobre a água é maior do que a capacidade que a planta tem em absorvê-la. É muito difícil determiná-lo em condições de campo sendo mais comum em laboratório, pela mesma metodologia utilizada para a $\mathrm{Cc}$, porém com as amostras submetidas à tensão de $15 \mathrm{~atm}$.

Outro método para determinar o Pm é intermédio da multiplicação da Cc e de coeficiente do solo. Esse é um método prático:

$\mathrm{Pm}=\mathrm{Cc} \cdot \mathrm{k}$

em que: $\mathrm{Cc}=$ capacidade de campo, $\%$ em peso e base seca; e $\mathrm{k}=$ constante, valor igual a 0,55 para solo com Cc entre 3 a $30 \%, 0,60$ para solo com Cc entre 31 a $55 \%$ e 0,70 para latossolo.

Densidade do solo (Ds): denomina-se Ds a relação entre a massa (Mss) e o volume (V) de uma amostra de solo seco.

$\mathrm{Na}$ seqüência segue um método prático para determinação da densidade do solo com uso do tubo de PVC e do forno microondas:
- Fazer a limpeza e umedecer o local para facilitar a coleta. Com o auxilio de dois tubos de PVC de $50 \mathrm{~mm}$ x $20 \mathrm{~cm}$ introduzi-los no solo $15 \mathrm{~cm}$ nas profundidades de 0 a $20 \mathrm{~cm}$ e de 20 a $40 \mathrm{~cm}$. Recomenda-se a amostragem de solo em pelo menos 3 pontos dentro da área ser irrigada. É normal a amostra compactar dentro do tubo, no entanto, o que importa é a coleta da massa referente à profundidade em questão (Figura 2).

- Depois de cravado no solo, retirar o tubo cuidadosamente. $\mathrm{O}$ excesso de solo na base deverá ser removido com canivete;

- A massa de solo contida no tubo deverá ser transferida para um saco plástico devidamente identificado: proprietário, setor, profundidade e ponto de amostragem;

- Espalha-se a amostra de solo úmida no prato giratório do forno microondas;

- Coloca-se o recipiente com solo dentro do forno microondas, com regulagem na potência máxima. Depois de 3 minutos, retira-se o recipiente do forno microondas e pesa-se a massa de solo;

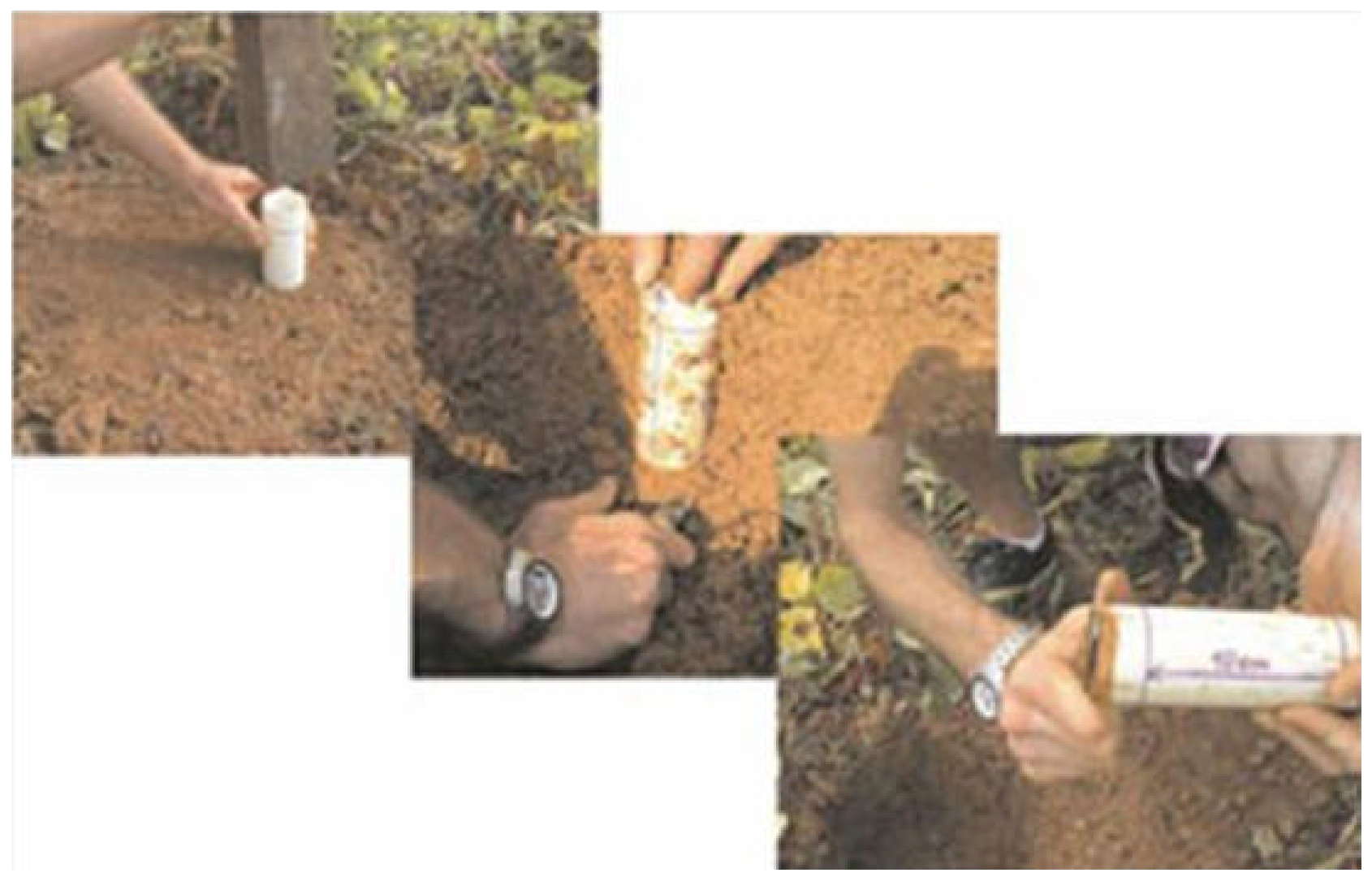

Figura 2 - Retirada e preparo de amostra de solo para determinação de sua densidade.

Fonte: Oliveira \& Ramos (2008). 
- Retorna-se o prato giratório com solo para o forno microondas, com a mesma regulagem. Depois de 1 minuto, retira-se o recipiente do forno microondas e pesa-se a massa de solo;

- A secagem do solo ocorrerá quando a leitura na balança se repetir (Mss); e

- Para altura do tubo igual a $15 \mathrm{~cm}$, mede-se o diâmetro do tubo (d) com um paquímetro e calcula-se o volume do anel da seguinte forma:

$\mathrm{V}=11,775 \cdot \mathrm{d}^{2}$

em que: $\mathrm{V}=$ volume do tubo, $\mathrm{cm}^{3}$; e $\mathrm{d}=$ diâmetro do tubo, $\mathrm{cm}$.

A densidade do solo é obtida da seguinte forma:

Ds $=\frac{\text { Mss }}{\mathrm{V}}$

em que: Ds = densidade do solo, $\mathrm{g} / \mathrm{cm}^{3} ;$ Mss = massa de solo seco, g; e $\mathrm{V}=$ volume do tubo, $\mathrm{cm}^{3}$.

Profundidade efetiva do sistema radicular ( $Z)$ : tanto em projeto quanto em manejo da irrigação é necessário o conhecimento da profundidade efetiva do sistema radicular e deve ser tal que, pelo menos, $80 \%$ do sistema radicular da cultura esteja nela contido. Ela depende da cultura e da profundidade do solo na área. Alencar (2007) avaliando a profundidade efetiva do sistema radicular em seis gramíneas irrigadas na região Leste do Estado de Minas Gerais encontrou os resultados relatados na Tabela 1 .

Tabela 1 - Valores de profundidade efetiva do sistema radicular (Z), para diversos capins irrigados

Capim Xaraés Mombaça Pioneiro Estrela Marandu

\begin{tabular}{llllll}
\hline $\mathrm{Z}(\mathrm{cm})$ & 45 & 45 & 50 & 60 & 65 \\
\hline
\end{tabular}

Capacidade total de água do solo (CTA): a CTA somente deve ser calculada até a profundidade do solo correspondente à profundidade efetiva do sistema radicular da cultura a ser irrigada (Figura 1), ou seja:

$\mathrm{CTA}=0,1 \cdot(\mathrm{Cc}-\mathrm{Pm}) \cdot \mathrm{Ds} \cdot \mathrm{Z}$

em que: $\mathrm{CTA}=$ capacidade total de água do solo, $\mathrm{mm}$; $\mathrm{Cc}=$ capacidade de campo, $\%$ em peso $; \mathrm{Pm}=$ ponto de murcha permanente, $\%$ em peso; Ds = densidade do solo, $\mathrm{g} / \mathrm{cm} ; \mathrm{e} \mathrm{Z}=$ profundidade efetiva do sistema radicular, $\mathrm{cm}$.

Fator de disponibilidade de água no solo (f): é um parâmetro que limita a parte da água disponível do solo que a planta pode utilizar, sem causar maiores prejuízos à produtividade e à qualidade. A sua proporção é definida em função do valor econômico, da sensibilidade da cultura ao déficit hídrico e da demanda evapotranspirométrica da região (Tabelas 2 e 3) (FAO, 1979). Em uma mesma cultura, quanto maior for a demanda evapotranspirométrica da região, menor deverá ser o valor de f (Tabela 3).

Capacidade real de água do solo (CRA): em irrigação, nunca se deve permitir que o teor de umidade do solo (umidade crítica - Uc, Figura 1) atinja o ponto de murchamento, isto é, deve-se somente usar, entre duas irrigações sucessivas, uma fração da capacidade total de água do solo, ou seja:

$\mathrm{CRA}=\mathrm{CTA} \cdot \mathrm{f}$

em que: $\mathrm{CRA}$ = capacidade real da água do solo, $\mathrm{mm}$; CTA = capacidade total de água do solo, $\mathrm{mm}$; e $\mathrm{f}=$ fator de disponibilidade de água no solo, adimensional.

Lâmina de irrigação real necessária (IRN): expressa a quantidade de água requerida pelo sistema para que a cultura se desenvolva sem déficit naquele determinado solo, sendo sempre inferior ou igual a CRA.

Tabela 2 - Grupos de culturas de acordo com a sensibilidade ao déficit de água no solo

\begin{tabular}{ll}
\hline Grupo & \multicolumn{1}{c}{ Cultura } \\
\hline 1 & Cebola, pimenta, batata, alface \\
2 & Banana, repolho, uva, ervilha, tomate, maracujá \\
3 & Alfafa, feijão, cítricas, amendoim, abacaxi, girassol, melancia, trigo, coco, goiaba, manga \\
4 & Algodão, milho, azeitona, açafrão, sorgo, soja, beterraba, cana, fumo, acerola, café, pastagem, pinha \\
\hline
\end{tabular}

Tabela 3 - Fator de disponibilidade de água no solo (f) em função do grupo de culturas e evapotranspiração de referencia (ETo)

\begin{tabular}{cccccccccc}
\hline Grupo de cultura & \multicolumn{1}{c}{ ETo (mm/dia) } \\
\cline { 2 - 10 } & 2 & 3 & 4 & 5 & 6 & 7 & 8 & 9 & 10 \\
\hline 1 & 0,50 & 0,42 & 0,35 & 0,30 & 0,25 & 0,22 & 0,20 & 0,20 & 0,18 \\
2 & 0,68 & 0,58 & 0,48 & 0,40 & 0,35 & 0,33 & 0,28 & 0,25 & 0,22 \\
3 & 0,80 & 0,70 & 0,60 & 0,50 & 0,45 & 0,42 & 0,38 & 0,35 & 0,30 \\
4 & 0,88 & 0,80 & 0,70 & 0,60 & 0,55 & 0,50 & 0,45 & 0,42 & 0,40 \\
\hline
\end{tabular}

Obs: recomenda-se os números em destaques para irrigação de pastagem. 
Lâmina de irrigação total necessária (ITN): deve-se acrescentar certa quantidade à IRN visto que durante a aplicação existem perdas como evaporação, arraste, desuniformidade e percolação. Para compensar essas perdas, divide-se a IRN pela eficiência de aplicação (Ea). Considerando que os sistemas de irrigação mais utilizados em pastagem são, Aspersão Semifixa e Pivô Central, recomenda-se, a favor da segurança, valor de Ea igual a $80 \%$.

A equação que descreve esse parâmetro é a seguinte:

$$
\mathrm{ITN}=\frac{\mathrm{IRN}}{\mathrm{Ea}}
$$

em que: ITN = irrigação total necessária, mm; IRN = irrigação real necessária, mm; e Ea = eficiência de aplicação, decimal.

\section{Turno de rega e jornada diária de serviço}

Entende-se por turno de rega, o intervalo compreendido entre duas irrigações sucessivas. E a jornada diária de serviço o número de horas diárias que o equipamento estará operando para aplicar uma determinada lâmina de água.

\section{Seleção de aspersores}

A escolha do aspersor utilizado no sistema de irrigação depende de alguns fatores, como: qualidade e quantidade de água, cultura a ser irrigada, tipo de solo (TIB), manejo da irrigação, intensidade e direção do vento e características do próprio aspersor, tais como: bocal, pressão de serviço, vazão e diâmetro molhado.

Os principais fatores que afetam o desempenho dos aspersores serão descrito a seguir:

Vento: quanto maior for a velocidade do vento, maior será o arraste da gota d'água que será aspergida pelo emissor, diminuindo a uniformidade de distribuição de água e afetando a eficiência de aplicação.
Tabela 4 - Espaçamento dos aspersores em função do diâmetro

\begin{tabular}{ll}
\hline Condições do vento & \multicolumn{1}{c}{ Largura da faixa } \\
\hline Sem vento & $\begin{array}{l}\mathrm{L}=80 \% \text { do diâmetro molhado } \\
\text { do aspersor }\end{array}$ \\
$<8 \mathrm{~km} / \mathrm{h}$ (fraco) & $\begin{array}{l}\mathrm{L}=70 \text { a } 80 \% \text { do diâmetro molhado } \\
\text { do aspersor }\end{array}$ \\
8 a $17 \mathrm{~km} / \mathrm{h}$ (moderado) & $\begin{array}{l}\mathrm{L}=60 \text { a } 70 \% \text { do diâmetro molhado } \\
\text { do aspersor } \\
\mathrm{L}=50 \text { a } 60 \% \text { do diâmetro molhado } \\
\text { do aspersor }\end{array}$ \\
\hline
\end{tabular}

Para diminuir os efeitos do vento, deve-se diminuir o espaçamento entre aspersores, dessa forma a uniformidade de distribuição e a intensidade de aplicação da água irão aumentar. Para contornar esse problema, também pode-se adotar aspersores com menor vazão e raio de alcance. Outro procedimento para diminuir a ação do vento é inserir as linhas laterais de forma perpendicular à direção dos ventos.

Na Tabela 4, encontra-se o espaçamento dos aspersores, em função do diâmetro de molhado e da intensidade do vento.

Pressão de serviço: as vazões dos aspersores são diretamente proporcionais à raiz quadrada da pressão de serviço. Um aspersor que funciona com o dobro de pressão de serviço fornecerá uma vazão $40 \%$ superior a outro. Diante disso, quando um projeto de irrigação apresenta aspersores funcionando com diferentes pressões de serviço, diferentes vazões serão aplicadas e conseqüentemente menores uniformidades de aplicação de água serão observadas.

Um dispositivo que corrige a diferença de pressão de serviço entre aspersores são as válvulas reguladoras de pressão (Figura 3). Essas válvulas reagem a um acréscimo de pressão de entrada (ou de saída, dependendo do tipo de válvula) diminuindo a seção de passagem de água e aumentando a perda de carga localizada que ocorre na

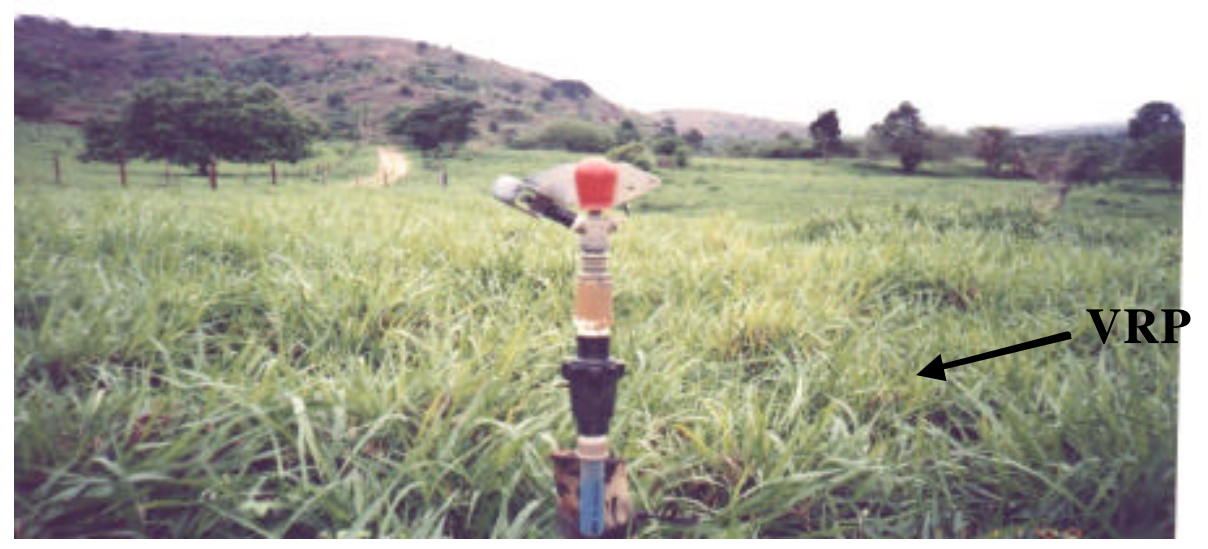

Figura 3 - Aspersor rotativo de baixa pressão e de um bocal, com válvula reguladora de pressão (VRP). 
válvula, de forma a compensar o aumento da pressão de entrada, mantendo a pressão de saída dentro de certos limites que irão caracterizar a "pressão de regulação da válvula".

Intensidade de aplicação (Ia)

A Ia é função da ITN e do tempo efetivo de irrigação por posição (Equação 8).

$$
\mathrm{Ia}=\frac{\mathrm{ITN}}{\mathrm{t}_{\mathrm{i}}}
$$

em que: Ia = intensidade de aplicação, $\mathrm{mm} / \mathrm{h}$; e ti = tempo de irrigação, h.

A intensidade de aplicação não deve ser maior que a taxa de infiltração básica do solo (TIB), para evitar problemas de escoamento superficial, de modo que se aplique a quantidade desejada de água. A TIB pode ser determinada pelo método do infiltrômetro de anel (Bernardo et al., 2007).

\section{Uniformidade de aplicação de água}

A medida da qualidade de uma irrigação por aspersão é sua uniformidade de distribuição de água. Esta uniformidade, normalmente expressa em termos de um coeficiente de uniformidade (CUC), tem sido freqüentemente a base para comparações da atuação da aspersão (Keller \&
Bliesner, 1990). Os valores de CUC definem um sistema de irrigação como excelente, bom, razoável, ruim e inaceitável (Tabela 5).

Impactos dos parâmetros de irrigação NA ETc E TR

Na Tabela 6 apresenta-se impactos dos parâmetros (capim, Kc, Z, textura do solo, ETo e f) na estimativa da lâmina de água (ETc) e do turno de rega (TR), em irrigação de pastagem, visando melhor entendimento dos mesmos. $\mathrm{O}$ ideal seria desenvolver pesquisas em nível regional para determinação desses fatores em cada tipo de capim, solo e sistema de pastejo. Como nem sempre isso é possível, recomendamos esses valores que podem ser utilizados como referência.

Os valores de referência de ETc (mm/dia) (Tabela 6) para as demandas evapotranspirométricas alta , média e baixa são 7,5; 5,0 e 2,5; respectiva mente. Os valores de referencia de TR (dias) para diferentes capins, texturas de solo e ETc podem variar de 1 a 34 dias.

Na Tabela 7 apresenta-se impactos dos parâmetros (TR e LB), na vazão, na potência, no custo de energia elétrica e no custo de equipamento, considerando sistema de irrigação por aspersão semifixa, visando melhor entendimento dos mesmos.

Tabela 5 - Classificação de acordo com a comparação dos valores de CUC para sistemas por aspersão

\begin{tabular}{lccccc}
\hline Classificação & Excelente & Boa & Razoável & Ruim & Inaceitável \\
\hline CUC $(\%)$ & $95-100$ & $85-95$ & $75-85$ & $65-75$ & $<65$ \\
\hline
\end{tabular}

Fonte: ASAE, 1996.

Tabela 6 - Turno de rega (TR) para diferentes capins, demandas evapotranspirométricas e texturas de solo

\begin{tabular}{|c|c|c|c|c|c|}
\hline \multirow[t]{6}{*}{ Capim } & \multirow[t]{6}{*}{$\mathrm{Z}(\mathrm{cm})$} & \multirow[t]{6}{*}{ Textura do solo } & \multicolumn{3}{|c|}{ ETo (mm/dia) } \\
\hline & & & Alta & Alta & Alta \\
\hline & & & 9,0 & 9,0 & 9,0 \\
\hline & & & \multicolumn{3}{|c|}{ ETc $(\mathrm{mm} / \mathrm{dia})$} \\
\hline & & & 7,5 & 7,5 & 7,5 \\
\hline & & & \multicolumn{3}{|c|}{ TR (dias) } \\
\hline \multirow{3}{*}{ Xaraés e Mombaça } & 45 & Arenosa & 1 & 2 & 8 \\
\hline & & Média & 3 & 5 & 15 \\
\hline & & Argilosa & 4 & 8 & 23 \\
\hline \multirow[t]{3}{*}{ Pioneiro } & 50 & Arenosa & 1 & 3 & 8 \\
\hline & & Média & 3 & 6 & 17 \\
\hline & & Argilosa & 5 & 9 & 26 \\
\hline \multirow[t]{3}{*}{ Estrela } & 60 & Arenosa & 2 & 3 & 10 \\
\hline & & Média & 4 & 7 & 21 \\
\hline & & Argilosa & 6 & 11 & 31 \\
\hline \multirow[t]{3}{*}{ Marandu e Tanzânia } & 65 & Arenosa & 2 & 4 & 11 \\
\hline & & Média & 4 & 8 & 22 \\
\hline & & Argilosa & 6 & 12 & 34 \\
\hline
\end{tabular}


Os valores de referência de Vazão ( $\mathrm{m}^{3} / \mathrm{h}$.ha) e de Potência (cv/ha) (Tabela 7) para as LB 9,4; 6,3 e 3,1 são 8,3; 5,2 e 2,7 $\mathrm{m}^{3} / \mathrm{h}$.ha e 2,$5 ; 1,7$ e $0,9 \mathrm{cv} / \mathrm{ha}$, respectivamente. Os valores de Energia (R $\$ /$ mês.ha) e de Equipamento ( $\mathrm{R}$ /ha) para diferentes capins, texturas de solo e LB podem variar de 35,60 a $147,60 \mathrm{R} \$ /$ mês.ha e $2.400,00$ a $5.500,00 \mathrm{R} \$ / \mathrm{ha}$, respectivamente.

Área sombreada não se recomenda devido aos fatores técnico (CRA, f), econômico e ambiental (uso eficiente da água).

\section{Custo de equipamento e de energia elétrica}

\section{Principais sistemas de irrigação}

No Brasil, o método de irrigação mais usado em pastagens é a aspersão e os sistemas mais utilizados são aspersão semifixa e pivô-central.

\section{Irrigação por aspersão semifixa}

Na década de 1990, foi desenvolvido um sistema de irrigação por aspersão semifixo de baixa pressão, que é um sistema em que as linhas principais, secundárias e laterais são em quantidades suficientes para irrigar toda a área. A condução de água da motobomba até os aspersores é efetuada por meio de tubulações de diversos tipos de material, como aço zincado, alumínio e PVC rígido. Apesar de as tubulações serem suficientes para irrigar ao mesmo tempo a área inteira, a irrigação é feita com funcionamento de determinado número de aspersores por vez, de acordo com o turno de rega (Alencar, 1999).

\section{Irrigação por aspersão pivô-central}

Desenvolvido na década de 1940 o sistema de irrigação por aspersão pivô-central, fundamentalmente, é constituído de uma tubulação metálica que se apóia em várias torres triangulares (o número de torres depende do tamanho da área), em que são instalados os aspersores, promovendo irrigação uniforme em uma área de superfície circular. Essa tubulação recebe água de uma adutora subterrânea, que vai até o "ponto do pivô" (dispositivo central), de onde o sistema se move continuamente por dispositivos elétricos ou hidráulicos instalados nas torres (Bernardo et al., 2007).

\section{Aspersão semifixa versus pivô central}

Cada um desses sistemas tem suas vantagens e limitações, de ordem técnica, econômica e ambiental. Não existem disponíveis na literatura científica dados conclusivos que definam o melhor sistema a ser utilizado, no entanto, analisando a Tabela 8 , é possível constatar a viabilidade da utilização do sistema de irrigação por aspersão

Tabela 7 - Estimativa da vazão ( $\mathrm{m}^{3} / \mathrm{h}$.ha), da potência (cv/ha), do consumo de energia elétrica (R \$/mês.ha) e do custo do equipamento (R \$/ ha) para sistema de irrigação por aspersão semifixo para diferentes turnos de rega (TR) e diferentes lâminas bruta (LB), considerando jornada de serviço de 12 horas, condição de vento moderado, linha de recalque de $30 \mathrm{~m}$ e altura manométrica de 50 m.c.a.

\begin{tabular}{|c|c|c|c|c|}
\hline \multirow{2}{*}{$\begin{array}{l}\text { TR (dias) } \\
1^{*}\end{array}$} & \multirow{2}{*}{$\begin{array}{l}\text { Irrigação (altura manométrica }=50 \mathrm{mca} \text { ) } \\
\text { Vazão }= \\
\text { Potência }= \\
\text { Custo de energia elétrica }= \\
\text { Custo de equipamento }=\end{array}$} & \multicolumn{3}{|c|}{ Lâmina bruta (mm/dia) } \\
\hline & & $\begin{array}{c}9,40 \\
8,30 \\
2,50 \\
147,60 \\
5.500,00\end{array}$ & $\begin{array}{c}6,30 \\
5,50 \\
1,70 \\
100,37 \\
5.000,00\end{array}$ & 3,10 \\
\hline $4^{* *}$ & $\begin{array}{l}\text { Vazão }= \\
\text { Potência }= \\
\text { Custo de energia elétrica }= \\
\text { Custo de equipamento }=\end{array}$ & $\begin{array}{c}8,30 \\
2,50 \\
98,90 \\
5.000,00\end{array}$ & $\begin{array}{c}5,50 \\
1,70 \\
67,24 \\
4.700,00\end{array}$ & \\
\hline $8^{* *}$ & $\begin{array}{l}\text { Vazão }= \\
\text { Potência }= \\
\text { Custo de energia elétrica }= \\
\text { Custo de equipamento }=\end{array}$ & & $\begin{array}{c}5,20 \\
1,70 \\
67,24 \\
3.500,00\end{array}$ & $\begin{array}{c}2,70 \\
0,90 \\
35,60 \\
3.000,00\end{array}$ \\
\hline $12^{* *}$ & $\begin{array}{l}\text { Vazão }= \\
\text { Potência }= \\
\text { Custo de energia elétrica }= \\
\text { Custo de equipamento }=\end{array}$ & & $\begin{array}{c}5,20 \\
1,70 \\
67,24 \\
3.000,00\end{array}$ & $\begin{array}{c}2,70 \\
0,90 \\
35,60 \\
2.600,00\end{array}$ \\
\hline $16^{* *}$ & $\begin{array}{l}\text { Vazão }= \\
\text { Potência }= \\
\text { Custo de energia elétrica }= \\
\text { Custo de equipamento }=\end{array}$ & & & $\begin{array}{c}2,70 \\
0,90 \\
35,60 \\
2.400,00\end{array}$ \\
\hline
\end{tabular}

\footnotetext{
* Irrigação diurna com tempo de irrigação por posição de 2 horas.
}

** Irrigação noturna com tempo de irrigação por posição de 12 horas. 
semifixa, que apesar de não permitir automação e financiamento através do FINAME, apresenta as seguintes características:

- De ordem técnica: funcionamento simples, podendo ser operado por qualquer pessoa, demandando pouca mãode-obra, sem necessidade de ser especializada;

- De ordem econômica: independência tecnológica, menor custo de aquisição, manutenção e gastos com energia elétrica, sendo condizente com a economia instável tanto nacional quanto mundial; e

- De ordem ambiental, ser um sistema que causa um menor impacto ao meio ambiente (menor desmatamento e menor potência instalada).

Ademais, o sistema de irrigação por aspersão semifixa apresenta menor intensidade de aplicação de água no solo quando comparado com o pivô central, podendo ser utilizado na maioria dos tipos de solos.

\section{Fertirrigação}

Em pastagens irrigadas, existe a possibilidade de aplicar fertilizantes juntamente com a água de irrigação. Ter um sistema de irrigação e não aproveitar a fertirrigação é um contra-senso, pois, quando comparado à forma convencional, possuem diversas vantagens. Segundo Feitosa Filho (1990), a adubação feita por métodos tradicionais possui uma eficiência máxima de 35 a 50\%, quando comparados com a fertirrigação.
Alguns fertilizantes utilizados na fertirrigação são: uréia e cloreto de potássio. A uréia quando incorporada parceladamente apresenta pequenas perdas por volatilização, porém quando aplicada de forma convencional, esta perda chega a $30 \%$. Já a fertirrigação com cloreto de potássio, existe o problema da sua menor solubilidade em água, que é de $370 \mathrm{~kg} / \mathrm{m}^{3}$, enquanto que a uréia apresenta solubilidade em água de $1.200 \mathrm{~kg} / \mathrm{m}^{3}$ (VITTI et al., 1995). A aplicação de fósforo por fertirrigação há mais controversa, em razão da reduzida mobilidade no perfil e do custo mais elevado das fontes solúveis em água.

\section{Tecnologia de aplicação e sistema de injeção}

Uma vez que o produto químico está misturado à água de irrigação, é necessário que a uniformidade de aplicação (CUC) seja elevada, para que se obtenha uma boa uniformidade de aplicação do produto. Independente do método de injeção adotado, a eficiência da fertirrigação depende do cálculo correto de variáveis como taxa de injeção, quantidade de produto a ser injetado, dose do produto a ser aplicado na área, concentração do produto na água de irrigação, entre outros.

A técnica mais simples e de baixo custo de injeção de solução química é a via sucção da bomba de irrigação (Figura 4). A pressão negativa, ou vácuo, é criada no interior do corpo da bomba e é transmitida para a tubulação de sucção do conjunto motobomba.

Tabela 8 - Comparação entre sistemas de irrigação com o número máximo de 20 horas/dia de funcionamento e lâmina bruta de 6,0 mm/ dia

\begin{tabular}{|c|c|c|}
\hline Sistema de irrigação & Aspersão semifixa & Aspersão pivô central \\
\hline Área (hectares) & 40 & 40 \\
\hline Lâmina(mm/mês) & 180 & 180 \\
\hline Vazão $\left(\mathrm{m}^{3} / \mathrm{h}\right)$ & 144 & 144 \\
\hline Turno de rega (dias) & 06 & 06 \\
\hline Altura manométrica (mca) & 60 & 60 \\
\hline Rendimento da bomba (\%) & 75 & 75 \\
\hline Rendimento do motor & 90 & 90 \\
\hline Potência do sistema (CV) & 50 & 60 \\
\hline Consumo médio de $\mathrm{KW} /$ hora & 40 & 45 \\
\hline Transformador (KVA) & 45 & 45 \\
\hline Custo do equipamento (US\$/ha)* & $1.000,00$ & $2.200,00$ \\
\hline Custo de manutenção ( $\mathrm{R} \$ /$ ha.ano) & 100,00 & 600,00 \\
\hline Custo de energia ( $\mathrm{R} \$ / \mathrm{mês}) * *$ & $4.423,20$ & $4.976,10$ \\
\hline Impacto ao meio ambiente & baixo & alto \\
\hline Vida útil média (anos) & 25 & 25 \\
\hline Declive do terreno $(\%)$ & s/restrição & até $20 \%$ \\
\hline Qualidade da mão-de-obra & normal & treinada \\
\hline Disponibilidade de mão-de-obra & baixa & baixa \\
\hline Automação & não & $\operatorname{sim}$ \\
\hline Fertirrigação & $\operatorname{sim}$ & $\operatorname{sim}$ \\
\hline Financiamento FINAME & não & $\operatorname{sim}$ \\
\hline
\end{tabular}

* Dólar $=\mathrm{R} \$ 2,20(15 / 04 / 2009)$

** KW/hora $=\mathrm{R} \$ 0,254$ (Tarifa normal); $\mathrm{R} \$ 0,090$ (Tarifa reduzida das 21:30 - 06:00 horas) Consumidor Classe B. 


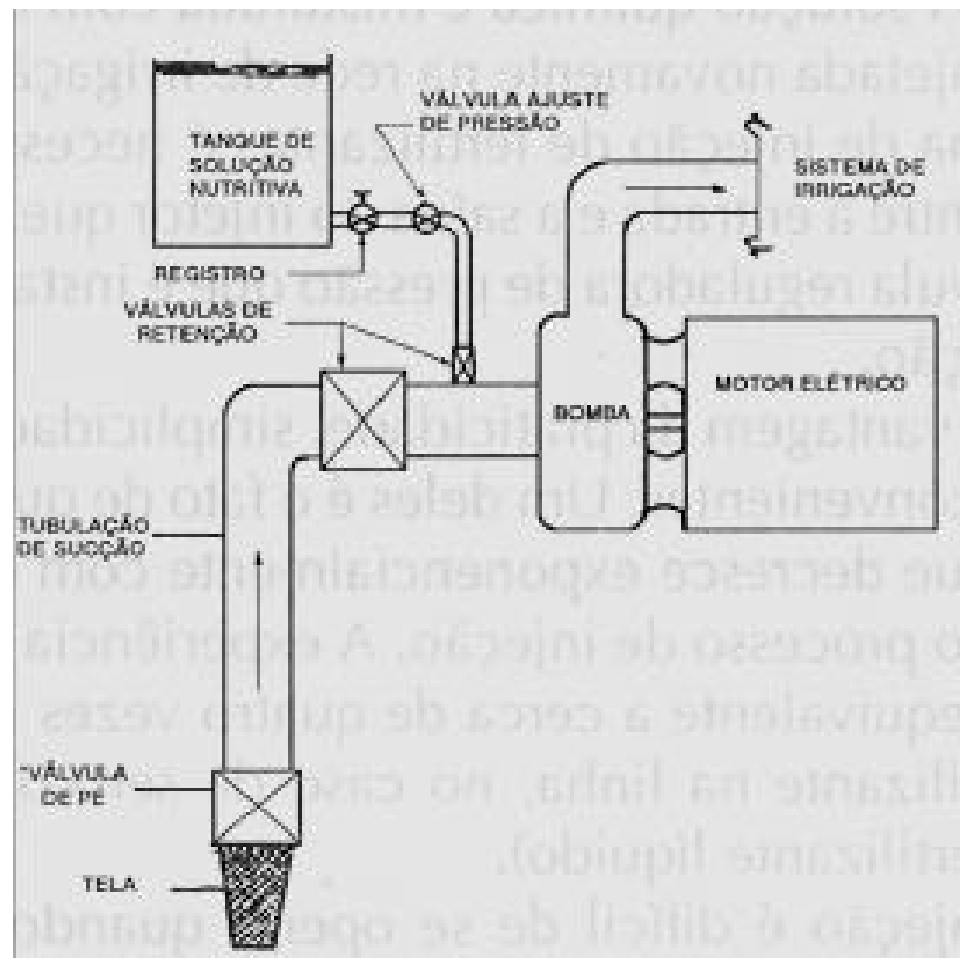

Figura 4 - Método de injeção de solução química a via sucção da bomba de irrigação.

\section{Pesquisa recente sobre fertirrigação em pastagem}

A pesquisa mais recente com fertirrigação em pastagem é a de C unha (2009), que estudou os efeitos da fertirrigação sobre a produtividade da MS do capim-xaraés submetido a diferentes períodos de desfolha e doses de nitrogênio e potássio, confrontando com adubação a lanço. Os resultados mostraram que a fertirrigação proporcionou maior produtividade de MS em relação à adubação convencional apenas nas maiores doses. Mesmo não havendo diferença em todos os tratamentos, o autor recomendou a utilização da fertirrigação, devido aos seguintes benefícios: redução dos custos de aplicação; evita-se a movimentação de máquinas na lavoura; a aplicação dos fertilizantes é feita com maior parcelamento da adubação; maior uniformidade de aplicação dos fertilizantes; menor risco de intoxicação de trabalhadores; e redução da contaminação do meio ambiente em conseqüência do melhor aproveitamento pelas plantas.

O detalhe dessa pesquisa é que a metodologia utilizada por Cunha (2009), "manejo integrado de irrigação e de adubação", quebra o paradigma "adubar a pastagem no máximo uma semana após a desfolha" e constrói outro paradigma "manejo da água e da adubação independem do manejo de pastagem", viabilizando o manejo da fertirrigação nas propriedades rurais, com um todo.

\section{Conclusões}

Os pecuaristas devem considerar todas as variáveis que influenciam os custos e rendimentos e eles continuarão a irrigar se os rendimentos em função do aumento de produção e da qualidade do produto compensar os custos de irrigação.

Infelizmente, muitos dos nossos pecuaristas tomam decisões mais pela emoção do que pela a razão, sendo assim vários sistemas são instalados sem que essas variáveis sejam determinadas e consideradas, e o resultado, como não poderia deixar de ser, sistemas que apresentam desempenho que deixa muito a desejar.

\section{Literatura Citada}

ALENCAR, C.A.B. Produção de seis gramíneas forrageiras tropicais submetidas a diferentes lâminas de água e doses de nitrogênio, na região Leste de Minas Gerais. 2007. 121f. Tese (Doutorado em Engenharia Agrícola) - Universidade Federal de Viçosa, Viçosa, MG, 2007.

ALENCAR, C.A.B. Sistema de produção de leite, cana-de-açúcar e pasto, irrigado por aspersão de baixa pressão. Glória Rural, v.3, n.27, p.13-19, 1999.

ASAE. American Society of Agricultural Engineers. Standard engineering practices data: EP 458. Field evaluation of microirrigation systems. St. Joseph: ASAE, 1996. p.792-797. BERNARDO, S; SOARES, A.A.; MANTOVANI, E.C. Manual de irrigação. 8.ed. Viçosa, MG: Editora UFV, 2007. 625p. 
BURKART, A. Evolution of grasses and grasslands in South America. Taxon, v.24, n.1, p.53-66, 1975.

CUNHA, F.F. Produção e características morfogênicas da Brachiaria brizantha cv. Xaraés com adubação convencional e fertirrigação na região Leste de Minas Gerais . 2009. 83f. Tese (Doutorado em Engenharia Agrícola) - Universidade Federal de Viçosa, Viçosa, MG, 2009.

DRUMOND, L.C.D.; FERNANDES, A.L.T. Irrigação por aspersão em malha. Uberaba: Universidade de Uberaba, $2001.84 \mathrm{p}$.

FEITOSA FILHO, J.C. Uniformidade de distribuição de fertilizantes via água de irrigação por microaspersão, com injetores tipo venturi e tanque de derivação . 1990. $77 \mathrm{f}$. Dissertação (Mestrado em Engenharia Agrícola) Universidade Federal de Viçosa, Viçosa, MG, 1990.

KELLER, J.; BLIESNER, R.D. Sprinkle and trickle irrigation. New York: Van Nostrand Reinhold, 1990. $652 \mathrm{p}$.
MANTOVANI, E.C.; BERNARDO, S.; PARALETTI, L.F. Irrigação princípios e métodos. 2.ed. Viçosa, MG: Editora UFV, 2007. $358 \mathrm{p}$.

OLIVEIRA FILHO, J.C.Produção de duas gramíneas tropicais submetidas a diferentes lâminas de água e doses de nitrogênio e potássio no Estado do Tocantins. 2007. 121f. Tese (Doutorado em Engenharia Agrícola) - Universidade Federal de Viçosa, Viçosa, MG, 2007.

OLIVEIRA, R.A.; RAMOS, M.M. Manual do irrigâmetro. Viçosa, MG: Os Autores, 2008. 144p.

VITOR, C.M.T. Adubação nitrogenada e lâmina de água no crescimento do capim-elefante. 2006. 77f. Tese (Doutorado em Zootecnia) - Universidade Federal de Viçosa, Viçosa, MG, 2006.

VITTI, G.C.; HOLANDA, J.S.; LUZ, P.H.C. et al. Fertirrigação: condições e manejo. In: REUNIÃO BRASILEIRA DE FERTILIDADE DO SOLO E NUTRIÇÃO DE PLANTAS, 21. 1994, Petrolina. Anais... Petrolina: Embrapa, 1995. p.195-271. 